\title{
Limites e possibilidade da construção de "territórios de desenvolvimento" na Região Serrana do Rio de Janeiro
}

\author{
Maria José Carneiro* \\ Betty Nogueira Rocha**
}

\section{Resumo}

O artigo propõe uma avaliação de dois projetos intermunicipais envolvendo agricultores familiares na construção social de territórios de desenvolvimento. Partiu-se da hipótese de que a construção dessa territorialidade é mediada por uma cultura política que imprime limites e condiciona as dinâmicas territoriais. O município de Nova Friburgo foi assumido como ponto de referência para o mapeamento de projetos e/ou ações mobilizando agricultores multifuncionais sediados em outras municipalidades da região serrana do Rio de Janeiro. Com base numa caracterização cursiva da trajetória de desenvolvimento do universo selecionado e na problematização da categoria de território, as autoras procuram elucidar de que maneira um traço constitutivo da sociedade brasileira - a patronagem e o clientelismo - opera na tentativa de construção territorial que tem os agricultores familiares como atores sociais e principais beneficiários das políticas públicas acionadas nos últimos tempos.

Palavras-chave: Desenvolvimento territorial sustentável, políticas públicas, agricultura familiar, clientelismo

* Doutora em Antropologia Social pela École des Hautes Etudes en Sciences Sociales. professora do Programa de Pós-Graduação de Ciencias Sociais em Desenvolvimento, Agricultura e Sociedade da Universidade Federal Rural do Rio de Janeiro.

*** Atualmente é doutoranda do Curso de Ciências Sociais em Desenvolvimento, Agricultura e Sociedade (CPDA) da Universidade Federal Rural do Rio de Janeiro. Tem experiência nas áreas de Economia Política, História do Pensamento Econômico e Ciências Sociais Aplicadas ao Estudo do Mundo Rural com ênfase no enfoque interdisciplinar ao estudo das migrações. 


\section{Introdução}

$\mathrm{O}$ presente estudo tem como foco de observação e análise dois projetos intermunicipais cujo público beneficiário é de agricultores familiares da região serrana do estado do Rio de Janeiro. Tais ações são vistas, no contexto desta pesquisa, como projetos coletivos, por mobilizarem atores sociais em torno de interesses comuns e recursos compartilhados, e por potencializarem a construção social de territórios de desenvolvimento. Partiu-se da hipótese de que a construção dessa territorialidade é mediada por uma cultura política que imprime limites e condiciona a dinâmica territorial. Nesse sentido, a identificação dos atores sociais envolvidos e das práticas implementadas foi o primeiro passo no sentido de contribuir para a reflexão sobre a construção de uma territorialidade que ultrapasse as fronteiras político-administrativas de uma municipalidade. Sem perder de vista o interesse maior da pesquisa em verificar como tais dinâmicas contemplam a agricultura familiar, observada através da lente da multifuncionalidade, pretende-se também verificar a sua contribuição (real ou potencial) para o desenvolvimento territorial.

Devido ao conhecimento acumulado por pesquisas anteriores, decidiu-se partir do município de Nova Friburgo como referência para o mapeamento de projetos e/ou ações que envolvessem agricultores de outras municipalidades. A ampliação do universo de observação ocorreu a partir da identificação dos projetos que serviam aos objetivos da pesquisa. Desta maneira, constata-se a existência de projetos coletivos que mobilizavam agricultores de quatro municípios além de Nova Friburgo: Sumidouro, Duas Barras, Bom Jardim e Teresópolis, todos pertencentes à referida microrregião.

Para desenvolvermos a reflexão proposta, apresenta-se inicialmente uma rápida caracterização do universo selecionado, seguido de uma problematização da categoria de território acompanhada do uso do conceito de patronagem no contexto estudado, para então atermos à análise dos dois projetos coletivos em foco e propor algumas considerações finais. 


\section{A região e as dinâmicas territoriais}

Esses municípios tiveram sua origem no decorrer do século XIX, atrelados à expansão da economia cafeeira na região. A instalação da Estrada de Ferro Leopoldina, em 1873, ajudou a dinamizar a economia, tornando-se um vetor de desenvolvimento para toda a região serrana, diminuindo distâncias, incrementando o comércio, o turismo e atraindo investimentos.

Nova Friburgo, um dos mais antigos municípios, inaugurou a colonização planejada no Brasil, em 1818, com a instalação de uma colônia de famílias suíças na Fazenda do Morro Queimado, no antigo Distrito de Cantagalo. Posteriormente, no período compreendido entre 1830 até o final do século, o desenvolvimento da monocultura do café estimulou o crescimento da produção agrícola, notadamente dos hortifrutigranjeiros, para o abastecimento das fazendas cafeeiras. Devido à sua posição geográfica, passagem obrigatória para o escoamento da produção cafeeira para a capital, Nova Friburgo foi consolidando-se como importante centro comercial e prestador de serviços. A existência da ferrovia possibilitou a instalação das primeiras indústrias têxteis no início do século XX, desencadeando importante processo de transformação socioeconômica com a atração de investimentos de capital nacional e estrangeiro. Paralelamente, sua potencialidade turística passa a ser explorada e incrementada pela construção de uma infraestrutura hoteleira. Atualmente, destaca-se como um importante polo de confecções de peças íntimas do vestuário feminino, em grande parte abrigada em espaços domésticos e trabalhada por membros de famílias urbanas e rurais.

Teresópolis, pela vasta cobertura vegetal e por suas formações rochosas, destacou-se também pelo turismo favorecido pela inauguração, em 1908, da ferrovia ligando-a à cidade do Rio de Janeiro. Diversas áreas de proteção ambiental estão localizadas na região, destacando-se o Parque Nacional da Serra dos Órgãos, criado em 1939, e o mais recente, Parque Estadual dos Três Picos, em 2002.

Atualmente, a região serrana tem se destacado pela horticultura para abastecimento das cidades, fazendo parte do cinturão verde do Rio de Janeiro, responsável por cerca de $90 \%$ produção de olerícolas do estado. A topografia acidentada não favoreceu 
a instalação de grandes propriedades, prevalecendo pequenos e médios estabelecimentos.

É significativa a utilização de trabalho exclusivamente familiar no conjunto dos municípios estudados, com exceção de Duas Barras, onde a presença de outras formas de relações de trabalho é igualmente relevante (diaristas, assalariados e parceiros). A parceria é uma forma de acesso à terra bastante praticada em toda a região, o que certamente contribui para o exercício da patronagem através de uma vasta rede de laços de dependência pessoal que, às vezes, são transmitidos de geração a geração. O contrato é verbal, baseado na confiança mútua e em uma ética sustentada no princípio da dívida moral entre partes, principalmente de baixo para cima. O pagamento pelo direito de se trabalhar na terra é feito em percentuais da produção que variam de acordo com o contrato estabelecido com o proprietário.

O escoamento da produção é um dos principais problemas enfrentados pelos agricultores, que têm de sujeitar-se à venda intermediada por atravessadores, posição às vezes concentrada na figura do proprietário de terra. Além disso, o fato de a maioria não possuir registro de produtor aumenta a dependência aos comerciantes que fornecem a nota fiscal como se tivessem sido eles próprios os produtores. Soma-se aos prejuízos causados aos pequenos agricultores por essa prática bastante difundida a evasão do ICMS do município produtor para o de Teresópolis, de onde provém grande parte desses atravessadores, contribuindo assim para a fraqueza orçamentária das secretarias de agricultura dos demais municípios. Há cerca de cinco anos, a Secretaria de Agricultura de Nova Friburgo iniciou uma grande campanha estimulando o cadastramento fiscal dos agricultores, com a finalidade de conhecer a capacidade produtiva do município e de aumentar a arrecadação municipal.

Nos últimos vinte anos observa-se um aumento acentuado da exploração do turismo com implicações sobre o uso do solo e sobre a especulação imobiliária, principalmente em Teresópolis e Nova Friburgo. O crescimento progressivo das habitações e sítios de lazer tem afetado também o mercado de trabalho no meio rural com a diversificação das oportunidades favorecendo a pluriatividade que, no entanto, não conteve a evasão da população rural para os 
centros urbanos. Esses dois municípios destacam-se como pólo dinamizador da economia da região, principalmente no que se refere à rede de comércio e serviços, incrementada pelo turismo, mas também nos aspectos políticos, culturais e educacionais. Essa dinâmica é responsável também pela atração de parte da população de cidades vizinhas, o que tem provocado o aumento da urbanização desses dois municípios, percebido pelo crescimento da ocupação dos morros nas periferias das cidades.

Pesquisas anteriores em Nova Friburgo apontaram para a dimensão multifuncional da agricultura familiar em dois aspectos: na manutenção do tecido social em que a atividade agrícola se manteve, seja como fonte de renda principal seja como renda complementar, e como garantia da segurança alimentar das famílias, ambos os fatores contribuindo fortemente para a reprodução social (CARNEIRO, 2003). Outra característica do papel da agricultura nesses municípios é a combinação com atividades não-agrícolas, com destaque para os serviços associados à exploração do turismo e à confecção. Onde isso ocorre observam-se os melhores índices de desenvolvimento humano, como é o caso de Nova Friburgo e Teresópolis. Ao contrário, os municípios cuja população rural vive quase exclusivamente da agricultura são os que apresentam os menores IDHs, o que coincide também com uma população rural proporcionalmente maior que a dos outros dois.

Em síntese, a dinâmica territorial dessa região é marcada pelos seguintes fatores:

- a diminuição do peso da agricultura como fonte de renda das famílias de agricultores. No entanto, essa atividade mantém a importante função como elemento de atribuição de identidade social, como produtora de alimentos para o autoconsumo e como estimuladora das redes de sociabilidade interfamiliares;

- a existência de várias unidades de conservação ambiental na região, associada à exploração do turismo, exerce uma pressão diferenciada na região, inibindo a atividade agrícola a favor da exploração do turismo ou pressionando para outras formas de produção agrícola, como a de tipo orgânica ou agroecológica;

- o turismo é um fator dinamizador desse território, ainda que venha exercendo pressões antagônicas sobre a população local, 
principalmente sobre os agricultores. De um lado, amplia o mercado de trabalho não-agrícola, oferecendo novas alternativas de renda à população local; de outro, reforça a coerção à agricultura quando esta passa a ser vista como agressiva ao meio ambiente, principalmente a que recorre a técnicas tradicionais, como a de 'pousio';

- a existência de um polo de confecções em Nova Friburgo tem demonstrado a sua relevância para agricultura familiar ao criar possibilidades de ampliação da renda das famílias com a instalação de confecções domésticas nas localidades rurais e em domicílios de agricultores.

\section{Território e patronagem}

Neste momento, alerta-se para a necessidade de reconhecer a diferença entre os estatutos da categoria território em diferentes contextos que a ela recorre. É importante que se identifique quando está sendo usada como instrumento de análise (no estatuto de categoria analítica) e quando assume o lugar de categoria operacional que organiza e orienta a ação humana, como, por exemplo, a intervenção através das políticas públicas e a administração pública em geral, aproximando-se do sentido dado por Pecqueur (1996) ao que ele nomeia de "território dado". Feita essa ressalva, este estudo lida com a dimensão conceitual-analítica dessa palavra. Isso implica reconhecer que outras acepções da noção são possíveis, sobretudo quando assumem o caráter de categoria operacional, ou seja, como instrumento de execução de políticas públicas.

Recentemente, o governo brasileiro implementou uma mudança de concepção aos projetos voltados para estimular o desenvolvimento rural ao optar por uma abordagem territorial, deixando para trás outras designações como as de desenvolvimento rural, local ou regional. Tal orientação pode ser entendida como uma tentativa de neutralizar os efeitos de uma cultura política centrada no poder local e, mais do que isso, no exercício da patronagem como princípio norteador das tomadas de decisão sobre a aplicação de recursos públicos.

Os projetos chamados de "desenvolvimento territorial", implementados pela Secretaria de Desenvolvimento Territorial (SDT) 
vinculada ao Ministério do Desenvolvimento Agrário (MDA), podem ser vistos, então, como uma alternativa apresentada à sociedade para as antigas práticas conhecidas na literatura clássica a partir de Oliveira Viana e Maria Isaura de Queiroz como 'mandonismo local'. Não se trata, no entanto, de afirmar a continuidade de uma cultura política tal qual se manifestara no século XIX e início do XX (LEAL, 1975). Certamente há de exigir-se rigor em aplicar os mesmos conceitos a relações políticas e sociais engendradas em conjunturas distintas (CARVALHO, 1998). Entende-se, como observa Cunha (2006), que as relações clientelistas não devem ser restritas a um determinado tempo histórico, como também não podem ser consideradas imutáveis ao longo da história. Elas têm duração maior, o que implica assumir que se transformam enquanto se reproduzem em seu essencial.

Nesse sentido, a análise aqui desenvolvida privilegiará a dimensão da cultura política presente na tentativa de execução de três projetos de intervenção pública, buscando identificar a manifestação da patronagem nas relações sociais engendradas no processo de elaboração e implementação. A escolha dos projetos como objeto de análise deve-se à hipótese subjacente de que tais projetos, por serem motivados por interesses de diferentes municípios, possam contribuir para a construção de territórios tal como foi esclarecido no capítulo dois da presente obra. Considerados, pelo marco teórico desta pesquisa, "projetos coletivos", eles distinguir-se-iam por serem supramunicipais, por terem uma relação com a agricultura familiar (contemplada no seu caráter multifuncional) ou com membros de famílias rurais, por envolverem dimensões materiais e simbólicas (que possam apontar para uma identidade territorial) e tenham reconhecimento social e político.

Nesse contexto, interessa investigar como a tentativa de construir projetos coletivos territoriais, de caráter supramunicipal, é vivenciada, seja pelos detentores do poder local (secretários municipais, por exemplo), seja por aqueles interessados na aplicação de recursos públicos. Apresenta-se, assim, uma questão-chave para orientar o questionamento aos dados: $\mathrm{O}$ que favorece a ruptura das fronteiras municipais na construção de projetos comuns que disputam por recursos públicos e, no sentido oposto, o que impede ou dificulta a transposição dessas fronteiras? 


\section{Os projetos coletivos e seus sujeitos}

A partir do mapeamento dos principais atores sociais comprometidos de alguma maneira com a agricultura familiar, dos projetos coletivos e programas públicos, observa-se um conjunto de ações que se diferenciavam por sua abordagem funcional e sistêmica do território. Nota-se que o entendimento e o uso que se faz da noção de território adquire nuances distintas, dependendo do enfoque conceitual utilizado. Neste sentido, o olhar analítico deste estudo seguiu três lógicas: (1) os fatores estruturantes entre os quais se destacam as dinâmicas socioeconômicas ou espaciais; (2) as políticas públicas através dos seus programas de âmbito municipal, estadual ou federal; e (3) os projetos coletivos supramunicipais que contemplassem os três critérios definidos à luz do enfoque da multifuncionalidade da agricultura.

O fio condutor da pesquisa de campo foi a primeira entrevista realizada com um representante da União das Associações e Cooperativas de Pequenos Produtores Rurais do Estado do Rio de Janeiro (Unacoop). Através das informações coletadas com a gerente da instituição, identificam-se alguns projetos coletivos que informam as tramas e enredos definidores das dinâmicas territoriais. Para além do ‘território dado' e para a finalidade deste estudo, foram selecionados como universo espacial de observação, afora de Nova Friburgo, os municípios de Sumidouro, Duas Barras, Bom Jardim e Teresópolis, todos pertencentes à região serrana do estado e relacionados entre si pelos objetivos comuns presentes nos "projetos coletivos".

Criada em dezembro de 1992 com o objetivo de representar e defender os interesses dos pequenos produtores rurais do estado do Rio de Janeiro, a União das Associações e Cooperativas de Pequenos Produtores Rurais do Estado do Rio de Janeiro administra o pavilhão 30 das Centrais de Abastecimento do Estado do Rio de Janeiro S.A. (Ceasa) destinado à comercialização dos produtos oriundos da agricultura familiar do estado. Além da gestão administrativa deste espaço, a entidade oferece assessoria técnica e jurídica; câmara fria para conservação dos produtos; cursos de capacitação em produção de insumos agroecológicos, embalagem, classificação e beneficiamento de produtos; representação política em espaços 
públicos; parcerias com prefeituras etc. Ela congrega, atualmente, cento e duas associações e cooperativas em todo o estado. Em Nova Friburgo são três associações de produtores filiadas, o que corresponde a um universo de 215 agricultores familiares; Teresópolis tem duas associações filiadas que representam 177 agricultores e, em Sumidouro, duas que agregam 443 agricultores. Não se tem registro de associados em Bom Jardim e Duas Barras.

Sua gestão é realizada por uma diretoria composta por onze agricultores eleitos em assembléia geral para o exercício de dois anos. Todo e qualquer agricultor filiado a uma associação ou cooperativa que seja associada da Unacoop pode candidatar-se a uma das vagas da diretoria. A fonte de renda da instituição é o pagamento da anuidade das associações e cooperativas afiliadas, bem como recursos provenientes de parcerias com a sociedade civil organizada e com o poder público nas suas esferas estadual e federal. A entidade tem se firmado como importante instituição na promoção de intercâmbio entre os agricultores familiares das diversas regiões do estado do Rio de Janeiro, com participação efetiva e constante no Conselho Estadual de Desenvolvimento Rural Sustentável (Cedrus) e nas oficinas territoriais promovidas no âmbito da política de desenvolvimento territorial da SDT/MDA.

Trata-se, portanto, de um importante agente mobilizador de atores sociais no meio rural do estado do Rio de Janeiro, o que resultou, por exemplo, na sua indicação para promover a articulação do recém-criado território rural Baía de Ilha Grande. Seu foco principal é possibilitar a comercialização e escoamento da produção dos agricultores, e para isto conta com diversas parcerias como o Instituto de Desenvolvimento e Ação Comunitária (Idaco), Empresa de Assistência Técnica e Extensão Rural do Estado do Rio de Janeiro (Emater), Associação de Agricultores Biológicos do Estado do Rio de Janeiro (Abio) Empresa de Pesquisa Agropecuária do Estado do Rio de Janeiro (Pesagro), SDT/MDA, programas governamentais voltados para a agricultura, dentre outros.

Identificam-se três eixos que orientam e informam as atividades desenvolvidas pela Unacoop: agroecologia, comercialização e associativismo/cooperativismo. Nesta perspectiva, surgiu o 'Projeto de Capacitação de Agricultores Familiares', cuja “demanda” foi “iden- 
tificada" por parte da gerente-geral da instituição, a qual propôs a capacitação de agricultores familiares no "manejo ecológico dos recursos naturais através de formas de ação coletiva (como associativismo e cooperativismo) em torno da organização comunitária e construção de uma unidade de produção de mudas agroecológicas em cada comunidade selecionada" ${ }^{1}$.

O termo agroecologia, quando aplicado a tais projetos ou quando mencionado pelos atores sociais entrevistados, não obedece a uma conceituação precisa. Em termos gerais, essa noção está associada e limitada à idéia de produção orgânica. Observou-se que o discurso político local é carregado das categorias "sustentabilidade", "agroecologia" ou "agricultura orgânica", o que recebe um sentido próprio no contexto atual em que tais categorias passaram a fazer parte do jargão político, principalmente quando o que está em jogo é a demanda de recursos públicos (CARNEIRO \& BRAGA, 2007). Como se sabe, a noção de sustentabilidade, normalmente articulada à de desenvolvimento, tornou-se referência obrigatória em quase todos os programas públicos governamentais e nãogovernamentais, principalmente após 1992.

No que se refere aos outros dois eixos temáticos, há uma convergência de objetivos já que, do ponto de vista estratégico, a organização dos agricultores em torno de associações ou cooperativas podem viabilizar e incrementar a comercialização de seus produtos. Não é intuito aqui discorrer sobre estes três eixos, mas apenas de reter estas informações como definidoras de um padrão que orienta as práticas e ações no território como se verá adiante na análise de outros projetos coletivos. Neste artigo retêm-se à análise do projeto de capacitação proposta pela Unacoop.

A atual diretora da entidade, ex-agricultora, foi "convidada pelos seus colegas" a assumir a gerência da entidade devido à sua "experiência no meio rural e relação de amizade e confiança mútua com os agricultores associados”, conforme explica. Esta relação

1 Fonte: Projeto de Capacitação de Agricultores Familiares. União das Associações e Cooperativas de Pequenos Produtores Rurais do Estado do Rio de Janeiro Unacoop. Programa Nacional de Fortalecimento da Agricultura Familiar - PronafCapacitação, 2003. 
confere-lhe uma autonomia ao representar a instituição nas mais diversas instâncias, muito embora faça questão de destacar que suas ações são todas "legitimadas pela diretoria".

Cabe destacar a forma como se deu o acesso à informação sobre o programa Pronaf-Capacitação ${ }^{2}$. Ela é reveladora do peso das relações pessoais sobre os procedimentos burocráticos e supostamente impessoais. A diretora da entidade soube da existência destes recursos através de um contato telefônico com o secretário estadual do Pronaf no estado do Rio de Janeiro, que a incentivou a elaborar uma proposta a fim de pleitear recursos.

Inicialmente, a capacitação foi proposta para os municípios de Nova Friburgo, Paracambi (município de origem da diretora da Unacoop) e Teresópolis, incorporando algumas de suas associações de produtores. Sustentando-se no argumento da restrição do prazo para apresentação do projeto, a seleção inicial das associações a serem beneficiadas baseou-se nas relações pessoais previamente existentes: relações de amizade e de confiança entre a proponente e os presidentes das associações escolhidas atuaram no convencimento dos agricultores associados a participarem. Tendo sido rejeitado, o mesmo projeto foi readaptado a novas exigências do Pronaf e reapresentado aproveitando a existência de uma "sobra de recursos". Nesse segundo momento, foram realizadas visitas às associações envolvidas, inicialmente com o intuito de "apresentar a idéia às comunidades", sob a justificativa de identificar e estimular o interesse dos agricultores. As diferentes etapas do projeto tinham por objetivo capacitar os agricultores familiares no manejo ecológico dos recursos naturais através de formas de ação coletiva (como associativismo e cooperativismo) em torno da organização comunitária e a construção de uma unidade de produção de mudas agroecológicas em cada comunidade. Após a apresentação formal da proposta, cada associação manifestou-se oficialmente (através de ata de assembléia ou reunião) sobre a sua adesão (ou não) ao projeto.

2 O Pronaf Capacitação é uma modalidade do Programa Nacional de Fortalecimento da Agricultura Familiar, com objetivo de fornecer recursos para projetos que contribuíssem para fortalecer a agricultura familiar e promover o desenvolvimento sustentável do meio rural. O público-alvo é o agricultor que precisa de capacitação e de assistência técnica. 
Duas associações "não se sentiram capazes de mobilizar os agricultores" e desistiram de participar. Para manter o caráter intermunicipal - exigência governamental - três associações de outros municípios vizinhos foram convidadas, tendo uma delas recusado o convite. Um novo convite foi feito à Associação de Produtores e Moradores de outro município não previsto até então, a qual aceitou participar, mais em virtude das relações institucionais (UnacoopAssociação) e pessoais entre agricultores e diretora da Unacoop do que propriamente pelo convencimento dos benefícios que seriam gerados com a participação no projeto.

Interessante registrar que todas as desistências foram baseadas no mesmo argumento: dificuldade em mobilizar os agricultores em torno de um curso de capacitação e instalação de unidade de produção baseados na prática agroecológica. As dificuldades realçadas pelas lideranças das associações em aderir ao cultivo de produtos agroecológicos são de cunho econômico (custo de produção elevado) e cultural (dificuldade e resistência de alguns agricultores em mudar o procedimento de cultivo). A chamada agroecologia exige, portanto, um esforço de convencimento, de "catequese", como diz alguns, que supõe também um processo educativo em rede em que a experiência de uns é repassada a outros na tentativa de aumentar o número de adeptos. No entanto, o principal argumento de convencimento continua sendo a experiência dramática resultante da contaminação ambiental e intoxicação humana, principalmente dos próprios produtores pelo uso excessivo de agrotóxico.

Apesar de os discursos dos gestores de política pública local enfatizarem o estímulo à produção "sustentável" ou "agroecológica”, os municípios da região serrana do Rio de Janeiro são grandes consumidores de insumos químicos na produção que abastece boa parte dos vegetais e folhas consumidos na capital. Mas é com o uso recorrente dos adjetivos sustentável ou agroecológico que secretários da agricultura tentam marcar suas gestões e angariar recursos para a agricultura.

Observa-se que, acima de todos os esforços despendidos para recrutar associações de produtores para os cursos de capacitação à produção agroecológica, são os compromissos que regem as relações pessoais, o mecanismo mais eficaz para se conseguir 
adesões. Desta maneira, pode-se inferir que esse projeto de capacitação cumpre também um importante papel no reforço dos laços pessoais entre agricultores e a diretora da Unacoop. Constitui, assim, um importante mecanismo de legitimação de sua autoridade como liderança local, o que the garante uma posição de destaque nas disputas internas nos espaços de concertação política sobre a agricultura fluminense, assim como nas disputas por recursos via projetos. Talvez se encontre aí um sentido para o esforço da diretora da Unacoop nesse processo de convencimento. Não seria demasiado entender esse empenho como um dos elementos de uma relação entre desiguais. A lógica que informa estas relações está embebida num padrão de reciprocidade desequilibrada, na qual a troca de favores alimenta a relação entre um mediador - aquele que tem acesso a informações ou domina as formas de acesso a recursos públicos (a Unacoop e sua representante) - e o prestígio e a lealdade conferidos pela "clientela" - os presidentes das associações (CANIELLO, 1990). Nesse caso, seguindo os princípios da patronagem, seriam entendidos como "favores" ou "bens" doados o conjunto de serviços prestados aos agricultores pela Unacoop através da mediação de sua diretora.

$\mathrm{Na}$ medida em que as categorias analíticas utilizadas pelo pesquisador constroem e moldam realidades de uma cultura (MARQUES, 1999), é importante destacar que, ao se fazer referência ao código da patronagem, reconhece-se a notável variabilidade etnográfica desse tipo de relação social e a utilização correlata ao conceito de clientelismo (CANIELLO, 1990) conforme referência anterior. Este exercício de análise aciona dados etnográficos que permitem avaliar como as estratégias e ações de atores em diferentes posições sociais são mediadas por linguagem de comportamento social específico, na qual a base ética se expressa nos idiomas da patronagem (GRYNSZPAN, 1990) e, por conseguinte, na complexa teia de relações pessoais, amizade, compadrio e, porque não dizer, clientelismo. Assim, a doação de sementes ou mudas seria um importante motor de dinamização das relações verticais que sustenta a posição da mediadora: "para você fazer um projeto para alguém, para algum órgão, você tem que contar toda uma história, tem que montar um enredo [...]. Então você tem que inventar uma coisa que 
não está a fim para poder conseguir o que você está a fim”, relata a diretora da Unacoop.

A montagem do "enredo" refere-se ao fato de os recursos pleiteados serem liberados apenas para propostas que visassem à capacitação e não investimentos, contrariando os interesses das associações de produtores normalmente voltados para investimentos (que podem ser entendidos também como objetos de "doações") que tragam melhorias para a comunidade ${ }^{3}$. Este dado exige um esforço maior da proponente do projeto no sentido de mobilizar pessoas para objetivos com os quais não se identificam.

Nós fizemos. O Pronaf Capacitação lá não poderia ter investimento, a Unacoop na hora entrou com investimento porque eles [os agricultores] só aceitavam fazer [o curso] com investimento. Eles acham que tem que deixar para o produtor alguma coisa para poder sentir que foi beneficiado. Ele não entende que a capacitação [por si] só, para ele, é um beneficio. Não é todo mundo que entende isto (Diretora da Unacoop).

Ainda que os recursos existentes não pudessem ser utilizados para reforçar as relações de troca de bens materiais, já que a capacitação não era vista como um "benefício", a estratégia da representante da união das cooperativas foi transferir a responsabilidade pela não-concessão do bem desejado pelos seus "clientes" - o investimento em infraestrutura ou a doação de sementes e insumos - para o governo federal que, como já se sabia, não aprovaria tais recursos. Sua posição de "batalhadora pelos interesses dos agricultores" seria assim confirmada e sua posição de mediadora na disputa pelo acesso a recursos públicos seria mantida. Este parece ser o objetivo principal dessa empreitada, mais importante que o conteúdo em si do que está sendo "ofertado" e do interesse dos clientes no bem ofertado. A patronagem afirma-se na medida em que os procedimentos de acesso aos recursos públicos exigem uma série de conhecimentos e de trâmites institucionais que não são facilmente

3 Sobre a relação entre gestão pública, lideranças das associações e produtores rurais como parte de uma rede de trocas de bens e favores, ver Carneiro e Braga (2007). 
manipulados pelos agricultores. Além disso, os espaços de representação não desempenham plenamente seu papel de institucionalizar a mediação entre os cidadãos e o poder público (MARQUES, 1999, p.139). Diversos autores como Campbell (1964), Herzfeld (1987) e Briquet (1998) argumentam que é neste sentido que a constituição de uma burocracia mais efetiva poderia configurar-se num fator limitante das relações assimétricas entre patrão e cliente, muito embora os dois sistemas coexistam sem excluírem-se mutuamente. A plasticidade destes sistemas é revelada em virtude de o código da patronagem subsistir quando e onde quer que a burocracia encontre dificuldade de instalar-se (HERZFELD apud MARQUES, 1999, p.140). A coexistência de relações de patronagem e a burocracia, o que Briquet (1998) chama de "clientelismo burocrático", baseia-se na monopolização das instituições controladas pelo Estado que fazem uso sistemático de recursos públicos para fidelizar a clientela e, com isto, reproduzir as condições materiais de sua hegemonia. Este argumento será retomado posteriormente.

Por outro lado, a falta de proporcionalidade da representação da categoria de agricultores familiares em relação à do poder público no Cedrus incentiva sobremaneira articulações baseadas em códigos de patronagem, quando se trata de garantir a aprovação de propostas que contemplem determinados grupos sociais. Embora o presente enfoque não privilegie a abordagem descrita no âmbito da política pública de desenvolvimento territorial promovida pelo MDA através da SDT, é importante destacar a interferência das proposições destas institucionalidades nas dinâmicas territoriais na área estudada.

Pode-se entender que o esforço da SDT em institucionalizar espaços de concertação intermunicipais caminharia na direção de instituir uma dimensão burocrática, impessoal e representativa que atuaria no sentido de romper com a dinâmica das relações pessoais, colaborando para isso a mobilização e representação de diferentes grupos sociais envolvidos na construção de "territórios de desenvolvimento". A ampliação das categorias sociais de sujeitas desse processo, promovida pelo próprio MDA, pode ser entendida como um passo importante nesta direção ao integrar pescadores, ribeirinhos, indígenas, quilombolas, artesãos, assentados e acampados da reforma agrária. A questão é que essa institucionalização não 
chega, ou não chegou ainda, a fundamentar uma nova cultura política alternativa às relações de troca de favores e de compromissos morais. Cabe indagar, no entanto, se tal mudança de práticas tão constitutivas da sociedade brasileira seria possível de ser realizada somente através dessas ações.

Outra experiência que vem confirmar tal interpretação foi a do processo de construção do projeto intermunicipal Organização da Produção e da Comercialização com Agregação de Valor à Produção Agrícola Rural ${ }^{4}$, com o objetivo de implantar uma unidade agroecológica para beneficiamento do caqui (como carro-chefe), tomate e maracujá, envolvendo os municípios de Nova Friburgo, Sumidouro, Carmo e Duas Barras. O projeto é resultado da negociação entre secretários de agricultura e extensionistas com o objetivo de candidatarem-se a recursos federais do Pronaf Infra-Estrutura Intermunicipal ${ }^{5}$.

A instalação da unidade foi justificada formalmente a fim de atender a uma norma do Ministério da Agricultura, Pecuária e Abastecimento no que se refere à padronização das embalagens e classificação dos produtos para garantir a uniformidade e agregar valor aos produtos. O curioso, no entanto, é que dos quatro municípios envolvidos apenas Sumidouro e Nova Friburgo têm produção expressiva de caqui. Embora se constate a insignificância da produção dos outros dois municípios, a presença deles no projeto era considerada fundamental para a sua aprovação, respeitando as novas exigências abordagem territorial de desenvolvimento. Além disso, justifica o extensionista, era uma oportunidade para que os próprios envolvidos "treinassem o território".

Trata-se de um projeto intermunicipal, cujo subproduto seria "treinar" a lógica territorial rompendo com a tradição da

4 Até o momento da realização da pesquisa de campo, o projeto ainda não tinha sido implementado; sua execução estava dependendo da liberação dos recursos pela Caixa Econômica Federal.

5 A resolução no 33, de 18 de agosto de 2003, do Conselho Nacional de Desenvolvimento Rural Sustentável (CNDRS) estabeleceu como regra na fase de transição da modalidade Pronaf-Infra para o Programa Nacional de Desenvolvimento Sustentável de Territórios Rurais (Pronat) que os projetos a serem financiados através desta modalidade deveriam ter um caráter de "integração entre municípios, no sentido de regionalidade das ações planejadas e complementares a

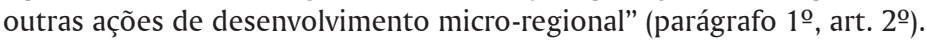


aplicação de recursos públicos, tendo como referência os interesses de um único município. A idéia aqui foi formalizar uma proposta que congregasse um conjunto de municípios com o objetivo de configurar a abrangência intermunicipal e possibilitar o acesso a recursos federais específicos. No entanto, cabe registrar que a idéia de elaborar esse projeto não incluía a preocupação prévia de envolvimento, sensibilização e mobilização dos atores sociais locais a serem beneficiados. $\mathrm{O}$ emprego da noção de "territorialidade" estava referido muito mais à seleção de produtos comuns aos municípios e à proximidade geográfica entre eles. É preciso não perder de vista que é justamente da relação do homem com o espaço em que vive, nas apropriações políticas e simbólicas desse espaço, que se estabelece uma territorialidade, sustentando e estimulando uma identidade territorial (HAESBAERT, 1995, p.78). Identifica-se, nesse caso, a intenção de exercitar uma dinâmica produtiva que extrapola os limites da municipalidade, cuja lógica operacional tem por base condicionantes geográficos (localização) e identitários (agricultores familiares). Todavia, persiste a lógica operacional da política de cima para baixo que, por um lado, é eficaz na proposição, articulação e aprovação nas instâncias decisórias e, de outro, é ineficiente devido aos entraves que dificultam a sua operacionalização como se verá a seguir.

Na proposta de implantação da unidade de beneficiamento, está prevista a criação de uma cooperativa que será responsável pela sua administração. A organização em torno de uma cooperativa faz-se necessária porque somente produtores organizados em cooperativas estão aptos a comercializar seus produtos. Existe uma questão fiscal (emissão de notas fiscais, por exemplo) e legal (legislação vigente) que normatiza a comercialização e, portanto, a necessidade de enquadramento.

O processo de construção deste projeto está diretamente relacionado com o VIII Encontro Técnico da Cultura do Caqui ${ }^{6}$, realizado no município de Duas Barras em julho de 2003, quando foi profe-

6 Segundo informações do técnico da Emater-Rio, esta atividade é promovida periodicamente pela Emater com objetivo de promover um espaço de debate e troca de informações entre os agricultores, técnicos etc. 
rida uma palestra sobre o processo de padronização, classificação, embalagem e comercialização de caqui pela Cooperativa Agrícola Sul de Minas (localizada em Turvolândia, Minas Gerais), despertando $\mathrm{o}$ interesse dos agricultores familiares presentes. $\mathrm{O}$ equipamento utilizado pela cooperativa de Turvolândia é automático: classifica a fruta a partir de critério de peso e aparência, garantindo não só a padronização e atendimento à legislação vigente como também agregando valor ao produto. Nos municípios envolvidos no referido projeto, o processo de classificação, padronização e embalagem ainda é feito manualmente, limitando a comercialização do produto em determinados nichos de mercados. Do interesse dos agricultores que participaram do encontro surgiu a idéia de elaborar um projeto visando a captar recursos e a viabilizar a instalação da beneficiadora. A responsabilidade pelo planejamento e elaboração da proposta foi de incumbência da Emater, da Pesagro, do Serviço de Apoio às Micro e Pequenas Empresas do Rio de Janeiro (Sebrae/RJ) e das prefeituras dos quatro municípios.

De acordo com a percepção de um extensionista, o interesse dos agricultores familiares em relação ao projeto guarda em si uma ambiguidade, pois ao mesmo tempo em que expressa a motivação dos agricultores na implantação da unidade de beneficiamento, revela como um dos entraves a falta de envolvimento e participação destes na concepção da proposta. Entende-se essa dificuldade como decorrente da própria falta de familiaridade com as práticas decisórias participativas nos espaços de concertação existentes, como também pela ausência de uma "cultura de cooperação" entre atores sociais com interesses distintos, como bem identificou um extensionista entrevistado:

Acho que com esse projeto a gente não consegue arrebanhar a maioria desses produtores, até porque formar uma cooperativa é um pouco complicado. É um conflito de interesses, né? Às vezes um puxa para um lado e outro puxa para o outro.

O fato de algumas cooperativas não terem dado certo serve de argumento para confirmar os receios dos agricultores produzindo um efeito negativo em suas avaliações. É como se o insucesso de um empreendimento refletisse sobremaneira as ex- 
periências de todos os demais e, daí, a dificuldade em "pensar em conjunto". Além disso, o conflito de interesses demarca as ações individuais comprometendo ações coletivas. Assim, o maior desafio identificado pelos próprios envolvidos nesse processo reside na constituição de uma cooperativa de produtores, que passaria a ser responsável pela gestão desta unidade.

Outro fator inibidor da mobilização dos agricultores na elaboração de projetos coletivos de desenvolvimento, apontado pelos secretários de agricultura, é o fato de que suas demandas nem sempre são aprovadas pelas instâncias decisórias superiores, desde as prefeituras até o Conselho Estadual de Desenvolvimento Rural Sustentável. A percepção de que suas demandas não são consideradas prioritárias por esses fóruns leva ao descrédito sobre o poder de decisão dos próprios agricultores e, por conseguinte, coloca em xeque a eficácia da política participativa. Além disso, algumas prefeituras atuam sistematicamente no sentido contrário à lógica da abordagem territorial de desenvolvimento, rejeitando por princípio qualquer demanda que venha dos Ciats. Como a liberação de recursos federais tem de ser feita pelas instâncias municipais, criou-se uma situação paradoxal que acaba por submeter a lógica territorial aos poderes locais, municipais. Como nem sempre as demandas dos agricultores familiares vão ao encontro dos interesses do poder público instituído (municipal, estadual ou federal), e como esse poder na maioria dos casos se sustenta em um padrão ético à base de relações pessoais, vislumbram-se duas alternativas: a mais convencional, na qual as demandas dos agricultores são negociadas na sala do secretário ou da prefeitura e sujeitas ao "comportamento generoso [do patrão] para com sua clientela" (CANIELO, 1990, p.49); outra possibilidade depende do peso das organizações locais no processo de legitimação das instâncias de representação e de concertação de abrangência territorial e supramunicipal, o que poderá ou não resultar na configuração de 'territórios' definidos acima. Interessante observar - e isso seria um bom assunto para ser desenvolvido em outra ocasião - é a maneira como a liderança local está apropriando-se da noção de território e atribuindo-lhe novos significados, em um processo de re-elaboração da percepção sobre os espaços de identidade, 
como sugere o presidente de uma associação de produtores: "As semelhanças [entre os municípios] são muito grandes, então você acaba tendo os mesmo problemas e processos. [...] A gente acaba criando, nem que seja pelas coisas ruins, uma identidade."

Da perspectiva da liderança e dos representantes das instituições públicas envolvidas, esta identidade "territorial" encontra-se ancorada em três fatores: a proximidade geográfica entre os produtores de municípios distintos, o que facilita a troca entre eles; o perfil comum da agricultura, baseada na organização familiar e na produção de olericultura; e a agroecologia como demarcadora de uma identidade territorial em potencial a ser explorada no futuro, já que a região observada desempenha um importante papel na produção estadual olerícula e sedia uma das certificadoras de produtos orgânicos do estado - a ABIO.

\section{Considerações finais}

Ainda que os projetos coletivos observados passem por um processo de encaminhamento que inclui, ao menos formalmente, a apresentação dos objetivos, a sua apreciação pelos possíveis beneficiados e a submissão à aprovação nos espaços de decisão coletiva, verificou-se que tais procedimentos não chegam a modificar (ainda?) as práticas decisórias sustentadas nas relações interpessoais. Foi possível constatar como um traço constitutivo da sociedade brasileira - a patronagem e o clientelismo - opera na tentativa de construção territorial que tem os agricultores familiares como atores sociais e principais beneficiários das políticas públicas acionadas.

Uma cultura política baseada na confiança pessoal e na dívida moral sustenta, por sua vez, a atuação dos mediadores, sejam esses presidentes de associações, lideranças de entidades privadas, secretários, prefeitos, representantes da sociedade civil em conselhos deliberativos etc. No entanto, foi possível perceber que esse tipo de relação colabora tanto para limitar a autonomia dos agricultores no processo de identificação de seus próprios interesses inibindo, assim, a sua participação na elaboração de projetos coletivos como, por outro, favorece a comunicação rápida entre pessoas e instâncias e engendrando processos que poderão, ou não, resultar na confor- 
mação desses "territórios".

Trata-se da constituição de redes que, apesar de relacionar representantes do poder público, sociedade civil e agricultores, guardam a capacidade de mobilização e negociação de atores sociais baseadas no código da patronagem e nos laços de lealdade e reciprocidade (GRYNSZPAN, 1990) visando à negociação de interesses que nem sempre são os explicitados. Constatou-se que, em parte, a manutenção e a ampliação dessas redes sociais de sustentação de determinadas posições de autoridade, assim como o fortalecimento de laços de lealdade e de reciprocidade, podem impor-se aos objetivos formais dos projetos em disputa.

Até aqui, atribuiu-se à lógica da patronagem, inevitavelmente, uma conotação negativa e crítica (GELLNER, 1997 apud MARQUES, 1999, p.138). Entretanto, há evidências de que este tipo de relação, paradoxalmente, viabilizou a elaboração de projetos coletivos que podem caminhar na direção da construção de territórios de desenvolvimento. Se não se recorresse às redes pessoais, dificilmente as primeiras experiências no sentido de conformar projetos coletivos teriam saído das boas intenções dos agentes das políticas públicas.

Todavia, as divergências e convergências das estratégias de negociação entre os atores da sociedade civil, motivados pelo processo de democratização ao acesso de recursos públicos, e os atores governamentais, preocupados com a gestão das políticas e manutenção de uma determinada posição nas relações de força na esfera pública, limitam, de maneiras diversas, a constituição de "territórios de desenvolvimento".

O panorama apresentado coloca em pauta o seguinte questionamento: para onde apontam as novas práticas da abordagem territorial de desenvolvimento para o meio rural? Retome-se então o argumento de Briquet (1998) sobre o "clientelismo burocrático". Para o autor, a análise dos

processos efetivos da modernização mostra, entretanto, que a formação e o desenvolvimento das instituições políticas modernas pode muito bem se acomodar às condutas clientelistas que participam do funcionamento das instituições e da realização concreta de seus objetivos sobre um território determinado (BRIQUET, 1998, p.36). 
Mais precisamente, a criação e institucionalização de novos espaços representativos denotam, sem dúvida, uma mudança na concepção do "fazer política", estimulando uma cultura política baseada na participação, negociação e concertação em torno de projetos e ações coletivas. Em termos empíricos, foi possível constatar que embora os casos analisados não estejam referenciados a um território rural institucionalizado pelo poder público (MDA), a idéia de 'treinar' a lógica territorial se fez presente, mas permeada de práticas clientelistas.

No que se refere à contribuição da agricultura familiar na construção de uma identidade territorial, observou-se uma situação paradoxal no que tange a tentativa das entidades envolvidas em imprimir a marca da "agroecologia" (ou orgânica) na produção desse território. Pois, se de um lado, um dos projetos coletivos analisados estava ancorado na idéia de estimular a produção 'agroecológica' via a capacitação de agricultores, por outro, algumas associações de agricultores recusaram participar devido à crença na resistência dos agricultores a essa idéia. Nesse sentido, a 'vocação' para um tipo de produção adaptada à conservação ambiental - tendo em conta a existência de diversas áreas protegidas - estaria sendo colocada em xeque pelas diversas dificuldades apontadas pelos próprios agricultores.

O projeto de capacitação de agricultores familiares para o "manejo ecológico dos recursos naturais" encontrou resistência não apenas em relação à conversão para a agroecologia, mas também no que diz respeito à organização coletiva através do associativismo e do cooperativismo. Percebem-se aí os limites de uma ação aparentemente participativa, resultante de uma "demanda identificada" pela instituição proponente. A reação encontrada por parte de certas associações aponta para um descolamento entre os interesses dos agricultores e os objetivos do projeto, o que vem corroborar com a idéia de que tais projetos não foram resultado da mobilização dos agricultores nem correspondiam aos seus interesses comuns. Tratase, sim, de um projeto que pretende atuar na direção de promover o desenvolvimento territorial que, ao partir de uma proposição de cima para baixo, depara com a resistência encontrada. É no mínimo precipitado concluir que ele tenha colaborado para potencializar a construção social de territórios. 
Finalmente, retomando a dimensão da multifuncionalidade da agricultura, observa-se que, de certa maneira, a tentativa de implementar um projeto pautado pela agroecologia acabou por excluir um segmento de agricultores, talvez os mais pobres, os com menor capacidade de suportar as perdas inicias da conversão, os com menor grau de informação e escolaridade, o que estaria comprometendo a capacidade potencial desses agricultores em exercer suas múltiplas funções. Não há informações que permitam avançar na qualificação desses excluídos nem dos que foram integrados ao projeto, mas deixa-se registrada a questão para possíveis desdobramentos futuros.

\section{Referências}

BRIQUET, J.L. La Politique Clientélaire. Clientélisme et Processus Politiques. In: BRIQUET, J.L. SAWICKI, F. Le Clientelisme Politique dans Les Sociétés Contemporaines. Paris: Presses Universitaires de France, 1998.

CAMPBELL, J.K. Honour, Family and Patronage: A Study of Institutions and Moral Values in a Greek Mountain Community. In: SCHMIDT, S. W. et al. Friends, Followers and Factions. A Reader in Political Clientelism. Oxford University Press, 1964.

CANIELLO, M. Patronagem e Rivalidade: Observações iniciais sobre processos de modulação ética numa cidade do interior. Revista Brasileira de Ciências Sociais, Rio de Janeiro, V. 5, n. 14, p. 46-58, 1990.

CARNEIRO, M.J. \& BRAGA, C.H. A idéia de sustentabilidade no "fazer política": o caso de um CMDRS no estado do Rio de Janeiro. In: Lima, E.; Delgado, N.G. \& Moreira, R.J. (Orgs.). Mundo Rural IV. Configurações rural-urbanas: poderes e políticas. Rio de Janeiro: Mauad, 2007.

CARNEIRO, M.J. Agricultura, meio ambiente e turismo: desafios para uma agricultura multifuncional. In: CARNEIRO, M.J \& MALUF, R. 
(Orgs). Para Além da Produção: Multifuncionalidade e Agricultura Familiar. Rio de Janeiro: Mauad, 2003.

CARVALHO, J.M. Mandonismo, coronelismo, clientelismo: uma discussão conceitual. In: Pontos e bordados: escritos de história e política. Belo Horizonte, UFMG, 1998.

CUNHA, A.M. Patronagem, clientelismo e redes clientelares: a aparente duração alargada de um mesmo conceito na história política brasileira. In: Revista História. São Paulo, v. 25, n. 1, 2006.

GRYNSZPAN, M. Os idiomas da patronagem: um estudo da trajetória de Tenório Cavalcanti. In: Revista Brasileira de Ciências Sociais, no 14, ano 5, 1990.

HERZFELD, M. Anthropology Through The Looking Class. Critical Ethnography in the Margins of Europe. New York/Cambridge: Cambridge University Press, 1987.

HAESBAERT, R. "Gaúchos no Nordeste" Modernidade, Desterritorialização e Identidade. Tese de doutorado. Faculdade de Filosofia e Ciências Humanas. Departamento de Geografia. USP, 1995.

LEAL, V.N. Coronelismo, enxada e voto. O município e o regime representativo no Brasil. São Paulo: Alfa-Omega, 1975.

MARQUES, A.C. Algumas faces de outros eus. Honra e patronagem na antropologia do Mediterrâneo. In: Mana. V. 5, n.1, 1999.

OLIVEIRA VIANNA, F. Instituições Políticas Brasileiras. Rio de Janeiro: Record, 1974.

PECQUEUR, B. (Ed.). Dynamiques territoriales et mutations économiques. Paris, L'Harmattan, 1996.

QUEIROZ, M.I. O Mandonismo local na vida política brasileira e outros ensaios. São Paulo: Alfa-Omega, 1976.

\section{Abstract}

Limits and possibilities for building "territories of development" in the Rio de Janeiro mountain region

This article proposes to evaluate two inter-municipal projects involving family farmers in the social construction of territories of development. 
Our starting point is the hypothesis that the building of this territoriality is mediated by a political culture that imposes limits and conditions territorial dynamics. The municipality of Nova Friburgo has been taken as a point of reference for the mapping of projects and/or actions that mobilize multi-functional farmers located in other municipalities of the mountainous region of the state of Rio de Janeiro. Based on a rapid characterization of the development trajectory of the chosen universe and on the problematization of the category of territory, we seek to elucidate the way in which a constitutive trait of Brazilian society - patronage and clientelism - operates within the context of family farmers' quest for territorial construction, as social actors and as the primary beneficiaries of the public policies that have been implemented in recent times

Keywords: Sustainable territorial development, public policies, family farming, clientelism. 
